\title{
UM NOME PARA CHAMAR DE MEU
}

\section{A NAME TO CALL MY}

\author{
Clarice Rocha Moreira Oliveira ${ }^{1}$ \\ Alexandra Gomes dos Santos Matos ${ }^{2}$
}

\begin{abstract}
RESUMO: Este trabalho é engendrado pela seguinte problemática: o Provimento $\mathrm{n}$. $73 / 2018$ do $\mathrm{CNJ}$ traz quais inovações normativas, no que tange ao direito de alteração do prenome dos transgêneros, nos cartórios de Registro Civil do Brasil? Para responder a essa questão, o objetivo geral desta pesquisa é analisar a alteração dos prenomes pelos transgêneros, nos Cartórios de Registro Civil das Pessoas Naturais do Brasil, enquanto um direito fundamentalmente humano, advindo da decisão do Supremo Tribunal Federal (STF), em controle abstrato de constitucionalidade, que motiva a edição do Provimento n.. 73, de 28 de junho de 2018, pelo Conselho Nacional de Justiça (CNJ). Para tanto, definem-se os seguintes objetivos específicos: identificar o lugar do transexual no curso da história do Brasil, reconhecendo as as ideologias de exclusão que demarcam esse processo, por meio de abordagens que abranjam os aspectos legais, sociais e culturais; reconhecer a necessidade e a importância do nome, de modo a dar relevo ao procedimento administrativo, constante no Provimento $\mathrm{n} . \stackrel{0}{73 / 2018}$ do CNJ, como importante baliza para a efetivação da dignidade humana, princípio basilar da Constituição da República Federativa do Brasil (CRFB/88) e especificar a regulamentação desse Provimento, evidenciando quais sejam os mecanismos necessários para que o requerente realize a alteração do prenome e do gênero, em respeito ao direito de pessoa humana dos transexuais. $\mathrm{O}$ artigo é bibliográfico e apresenta coleta de dados qualitativa. $\mathrm{Na}$ pesquisa, verificam-se os avanços sociais, assim como os constitucionais do direito dos transgêneros, sendo um deles a alteração do prenome e do gênero, enfatizando a sua relevância, no âmbito social, no sentido de que o sujeito é identificado por meio do prenome. A partir disso, analisa-se o procedimento adotado para que essa alteração seja realizada pela via extrajudicial.
\end{abstract}

PALAVRAS-CHAVE: Direito ao nome; Gênero; Prenome; Procedimento Extrajudicial; Transgêneros.

\footnotetext{
${ }^{1}$ Bacharela em Direito pela Faculdade de Ciências Empresariais (FACEMP).

${ }^{2}$ Mestra e graduada em Letras Vernáculas pela Universidade do Estado da Bahia (UNEB); Bacharela em Direito e especialista em Estudos Linguísticos e Literários pela Universidade Federal da Bahia; Especialista em Direito Educacional pela Faculdade Futura; Professora efetiva de Língua Portuguesa, de Literatura Brasileira e de Direito Constitucional, na condição de Servidora Pública da Secretaria de Educação do Estado da Bahia; Docente do Colégio Santo Antônio de Jesus (Sistema COC de Ensino); Integrante do Grupo de Pesquisa Múltiplas Linguagens da UNEB.
} 
ABSTRACT: This work is engendered by the following issue: CNJ Provision No. $73 / 2018$ brought which normative innovations, regarding the right to change the first name of transgenders, in the Civil Registry Offices of Brazil? Therefore, the general objective of this research is to analyze the change of first names by transgender people in the Civil Registry of Natural Persons in Brazil, as a fundamentally human right, arising from the decision of the Supreme Court (STF), in abstract constitutional control , which motivates the issue of Provision No. 73, of June 28,2018 , by the National Council of Justice (CNJ). Therefore, the following specific objectives were defined: to identify the transsexual's place in the course of Brazilian history, recognizing the exclusion ideologies that demarcate this process, through approaches that encompass legal, social and cultural aspects; recognize the need and importance of the name, in order to emphasize the administrative procedure, contained in CNJ Provision No. $73 / 2018$, as an important guide for the realization of human dignity, a basic principle of the Constitution of the Federative Republic of Brazil ( CRFB/88) and specify the regulation of this Provision, evidencing the necessary mechanisms for the applicant to change the first name and gender, in respect of the human rights of transsexuals. The article is bibliographic and presents qualitative data collection. In the research, there are social advances, as well as the constitutional advances of transgender law, one of which is the change of the first name and gender, emphasizing its relevance, in the social sphere, in the sense that the subject is identified through the given name. From this, the procedure adopted for this change to be carried out extrajudicially is analyzed.

KEYWORDS: Right to name; Genre; First name; Extrajudicial Procedure; Transgenders.

\section{INTRODUÇÃO}

A identificação das pessoas, na vida em sociedade e familiar, é realizada por meio do nome. Nessa perspectiva, Carlos Roberto Gonçalves (2017) observa que ele é composto pelo prenome, assim como pelo sobrenome e é de suma relevância no âmbito social, garantindo os direitos e deveres, na ordem civil, aos sujeitos. O Código Civil (CC), em seu artigo 16, caput, corrobora essa premissa quando afirma que "toda pessoa tem direito ao nome, nele compreendidos o prenome e o sobrenome". (BRASIL, 2002, on-line).

Nesse sentido, ter um nome para chamar de seu é se identificar com ele. Embora não tenha sido escolhido pela pessoa que o porta, ele vai representá-la para os mais diversos atos da vida civil. Nem sempre a prole vi estar satisfeita com a escolha de seus progenitores, quando estiverem na fase adulta. Essa situação traz impactos negativos para a pessoa por gerar tristeza, insatisfação, além de outros sentimentos não compatíveis com a valorização da dignidade humana. A situação dos 
transgêneros é ainda pior, enquadram-se nas minorias, não seguindo o padrão do binarismo sexual, isto é, não se inserem como integrantes do sexo masculino ou feminino. Assim sendo, os transgêneros possuem uma identidade de gênero, diferente do sexo observável desde o seu nascimento.

O direito pátrio nem sempre abrange os transgêneros. Por isso, no decorrer da história do Brasil, eles são excluídos socialmente, sendo a luta pela igualdade uma constante. Como consequência disso, o Procurador Geral da República (PGR) ajuizou

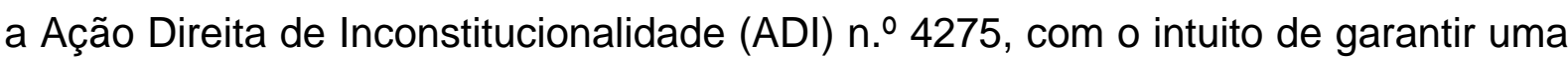
vida, com mais dignidade, para esses sujeitos, requerendo os direitos deles de alterarem o prenome e o gênero, em registro civil, sem necessidade de cirurgia de redesignação de sexo. Na oportunidade, o Supremo Tribunal Federal (STF) dá melhor interpretação ao artigo 58 da Lei 6.015/73, à luz do que determina a Constituição da República Federativa do Brasil (CRFB/88). A decisão baseada no princípio constitucional da dignidade da pessoa humana tem efeito erga omnes por se tratar de controle constitucional abstrato.

O Conselho Nacional de Justiça (CNJ), por seu turno, publica o Provimento n. ${ }^{\circ}$ 73/2018, caracterizado como uma grande conquista para os brasileiros, por reconhecer o direito dos transgêneros de realizar a alteração nominal em cartório de registro civil. Dada a relevância da regulamentação desse Provimento e a existência de poucas pesquisas sobre esse assunto, pergunta-se: o Provimento n. ${ }^{\circ}$ 73/2018 do CNJ traz quais inovações normativas, no que tange ao direito de alteração do prenome dos transgêneros, nos cartórios de Registro Civil do Brasil?

Essa mudança nominal, em tempos nem tão remotos assim, tem maior complexidade, não bastando apenas a vontade própria do indivíduo. Nesse caso, para ter essa autorização, é exigido que o judiciário seja provocado e de que o requerente tenha feito a cirurgia de redesignação de sexo, o que é modificado pelo provimento 73/2018, publicado pelo CNJ. A partir disso, enfatiza-se a possibilidade de alteração do prenome e do gênero em registro de nascimento/casamento, no cartório, de forma extrajudicial, com o fito de garantir o direito fundamental daquele que assim o deseja, de forma mais rápida. 
Porém, por se tratar de uma decisão recente, nem sempre o público alvo tem acesso a ela, sendo a publicidade do procedimento, em epígrafe, de sumo relevo para consolidação do direito à felicidade. Este trabalho, nesse sentido, tem especial importância por dar notoriedade a um direito humano e defender essa premissa de forma, amiúde. Para tanto, é esclarecido, inicialmente, que a alteração nominal, de que trata o provimento do $\mathrm{CNJ}$, só pode ser concretizada se o requerente for maior de 18 anos. Mas, apenas isso não basta, é preciso que esteja portando toda documentação exigida nesse Provimento.

Conforme Artur Francisco Mori Rodrigues Mota, muitos transexuais não têm “[...] acesso à informação e são muitas as certidões exigidas. São documentos difíceis de serem achados em diversos sites de tribunais de justiça e isso requer, no mínimo, que se tenha internet". (MOTA, 2020, on-line). Sendo assim, não basta apenas chegar ao cartório e requerer a retificação do registro, é preciso estar portando toda documentação exigida, devidamente atualizadas. Ademais, a linguagem desse Provimento é complexa, o que dificulta o acesso de grande parte da população, sem escolaridade necessária para compreensão textual. Destarte, sobreleva-se o valor social deste trabalho, por viabilizar acesso amplo à informação, ao se servir de uma linguagem simples.

Nessa linha, a presente pesquisa analisa a alteração dos prenomes pelos transgêneros, nos Cartórios de Registro Civil das Pessoas Naturais do Brasil, enquanto um direito fundamentalmente humano, advindo da decisão do Supremo Tribunal Federal (STF), em controle abstrato de constitucionalidade, que motiva a edição do Provimento $n . \stackrel{0}{73}$, de 28 de junho de 2018, pelo Conselho Nacional de Justiça (CNJ). Buscando concretizar esse propósito, são definidos os seguintes objetivos específicos: identificar o lugar do transexual no curso da história do Brasil, reconhecendo as ideologias de exclusão que demarcam esse processo, por meio de abordagens que abranjam os aspectos legais, sociais e culturais; reconhecer a necessidade e a importância do nome, de modo a dar relevo ao procedimento administrativo, constante no Provimento . $^{\circ} 73 / 2018$ do CNJ, como importante baliza para a efetivação da dignidade humana, princípio basilar da Constituição da República Federativa do Brasil (CRFB/88) e especificar a regulamentação desse Provimento, 
evidenciando quais sejam os mecanismos necessários para que o requerente realize a alteração do prenome e do gênero, em respeito ao direito de pessoa humana dos transexuais.

Neste trabalho, adota-se a revisão bibliográfica, como a define Gil (2002), sendo a coleta de dados nos moldes qualitativos. Chizzotti (2003) entende que essa é a forma mais adequada de se realizar estudos científicos em ciências sociais por exigir uma maior sensibilidade do pesquisador, analisando os resultados a partir do contexto histórico e dos aspectos sociais e jurídicos a ele atrelados. Destarte, este trabalho está organizado em cinco tópicos. Após esta parte introdutória, que delineia as linhas gerais da pesquisa, inicia-se o segundo tópico, no qual se realiza um breve resumo da transexualidade no Brasil, passando a observar as implicações legais que cada momento acarreta para o âmbito jurídico.

No terceiro tópico, é exposta a importância do nome, como forma de implementar a dignidade da pessoa humana, observando que ele se desvincula da identidade com a qual os transgêneros se identificam. Por ser diferente daquele adotado no registro de nascimento, que é o primeiro documento do ser humano, o nome se caracteriza como o direito fundamental para o pleno exercício de sua vida civil. Por isso, a relevância dele, meio pelo qual o indivíduo se identifica sem que, para isso, sofra qualquer tipo de constrangimento.

Posteriormente, no quarto tópico, é feita uma análise sobre o Provimento $n$. $^{\circ}$ 73/2018 do CNJ, suas implicações para a vida dos transgêneros, percebendo-o como um processo mais célere para concretização do direito à mudança do prenome que, porventura, o indivíduo deseje pleitear. Nesse toar, passa-se a discutir sobre o procedimento extrajudicial e os documentos necessários para requerer essa alteração nominal, tema dobre o qual se deleita este trabalho.

Por fim, nas considerações finais, verificam-se os resultados da pesquisa, demonstrando a evolução dos direitos humanos, a importância de se criar um procedimento na esfera extrajudicial para facilitar o acesso do requerente a essa alteração. Nesse sentido, é visualizado o avanço que os transexuais vêm alcançando no curso da história do pensamento jurídico brasileiro. 


\section{A TRANSEXUALIDADE NO BRASIL}

A dignidade humana é erigida como Princípio basilar da CRFB/88. Porém, nem sempre essa prática é recorrente no ordenamento jurídico brasileiro, pois ficam de fora desse processo as minorias sociais, como por exemplo, lésbicas, gays, bissexuais, travestis, transexuais, queer (LGBTIQ+) ${ }^{3}$. No Brasil, a aprovação dessa terminologia se dá por meio de uma conferência, realizada em 2008, como forma de debater políticas públicas mais eficazes em promoção dos direitos humanos. Dada a importância desse direito para a consolidação da dignidade humana, impera verificar como essa temática é abordada, no decorrer da história do Brasil, e as suas implicações para o ordenamento jurídico.

A transexualidade está vinculada ao indivíduo que possui uma identidade de gênero diferente daquela do nascimento, o que desperta o desejo de viver e de ser aceito como sendo do sexo oposto. A partir disso, há a necessidade da pessoa ser reconhecida pela identidade autopercebida e vivida, pois o nome registral the causa constrangimentos, o que não coaduna com os ideias de dignidade humana da CRFB $/ 88^{4}$. Estes são efetivados, em plenitude, à medida que o cidadão tenha os direitos fundamentais consolidados. Entre eles, em especial, estão os de primeira dimensão $0^{5}$ que tratam das ideias de liberdade individual, como o direito ao nome e à

\footnotetext{
${ }^{3}$ Segundo o site da Universidade de São Paulo (USP), o grupo que compreende o LGBTQ+ deve ser assim classificado: "Lésbicas - Mulheres cis ou transgênero que possui uma relação homoafetiva com outra mulher; Gays - Homens cis ou transgênero que possui uma relação homoafetiva com outro homem; Bissexuais - Pessoas que sentem atração (afetiva ou sexual) por ambos os sexos; Transgênero - Expressão usada para designar casos de pessoas que assumem um gênero diferente do sexo biológico ou transita entre os sexos; Intersex - uma variação nas características sexuais, incluindo cromossomos, gônadas ou órgãos genitais que não permitem que um indivíduo seja identificado distintamente como homem ou mulher; Questionando - O questionamento do sexo, identidade sexual, orientação sexual ou dos três é um processo de exploração por pessoas que podem estar inseguras, ainda explorando e preocupadas em aplicar um rótulo social a si mesmas por várias razões. Ainda conforme o referido site, "As pessoas costumam usar LGBTQ+ para significar todas as comunidades incluídas no "LGBTTTQQIAA+". Além dessas citadas acima, gênero e sexualidade é um espectro muito grande que abrange muitos mais grupos. Esses grupos variam entre orientação sexual, identidade de gênero, expressão de gênero". (UNIVERSIDADE DE SÃO PAULO, 2018, on-line).

${ }^{4} \mathrm{~A}$ Constituição Federal determina no art. $1^{\circ}$, inciso III, que a dignidade da pessoa humana é um dos princípios pelo qual se constitui a República Federativa do Brasil. Nesse compasso, o artigo quinto expõe direitos fundamentais que garantem de que modo será consolidada essa dignidade.

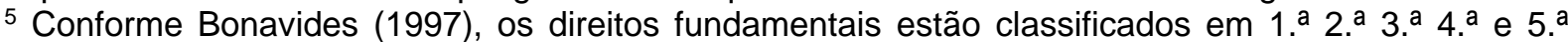
dimensões. Estão elencados, na primeira dimensão, caracterizados como direitos individuais, aqueles que garantem as liberdades públicas, civis e políticas, marcando a passagem do Estado absolutista
} 
felicidade, reconhecendo-os como um direito de todo ser humano, independente de quem seja o indivíduo.

Felipe Mendonça Montenegro (2015), ao empreender estudo sobre essa temática, no Brasil, realiza um artigo, denominado "A realidade do transexual perante a previdência social", como Trabalho de Conclusão de Curso para a especialização em Direito Público, na Escola da Magistratura Federal do Rio Grande do Sul, no ano de 2015. Nessa pesquisa, fica evidente o tratamento não compatível com os ideais de dignidade humana a que esses indivíduos são submetidos, sendo tratados com "doentes mentais", como se verifica:

Ao analisar na história, os primeiros casos relatados sobre o transexualismo constatam-se pelos registros, que estes indivíduos sempre estiveram à margem da sociedade. Os primeiros casos conhecidos pela psiquiatria receberam inicialmente diagnósticos que os enquadravam como doentes mentais, portadores de desvios comportamentais sexuais, trazendo aos membros desta minoria a estigma de possuírem uma patologia, conforme foi o registro do Manual Estatístico e Diagnóstico de Doenças Mentais (DSM I6), publicado em 1952. (MONTENEGRO, 2015, p.4).

Diante do exposto, percebe-se que o indivíduo é inferiorizado por sua identidade de gênero ser diferente do binarismo ${ }^{7}$, aceito socialmente, havendo um grande desrespeito à dignidade da pessoa humana. Nesse sentido, importa sublinhar

para o liberal. Na segunda dimensão, são elencados os direitos sociais, culturais e econômicos, como também os direitos coletivos, demarcando um Estado intervencionista, isto é, social. A terceira dimensão, por seu turno, é caracterizada pelo preservacionismo ambiental, o chamado Estado fraternal e solidário, no qual o ser humano passa a ter centralidade, sendo inserido em uma coletividade, com direitos transindividuais. A quarta dimensão relata os avanços na engenharia genética, caracterizado por Bonavides (1997, p.569), como "globalização política". Por último, não menos importante, a quinta dimensão fala sobre o direito à paz, devendo ser tratada como uma dimensão autônoma, nos termos de Bonavides (1997).

6 O Manual diagnóstico e estatístico de transtornos mentais (DSM), da American Psychiatric Association, classifica, nas palavrs de Montenegro, "[...] transtornos mentais e critérios associados para facilitar o estabelecimento de diagnósticos mais confiáveis desses transtornos". (MONTENEGRO, 2015, p.15).

${ }^{7}$ Segundo Sant'ana e et. al. (2019), no capítulo intitulado "Uma discussão sobre identidade de gênero e orientação sexual no Comportamentalismo Radical", que compõe o livro publicado pela Associação Brasileira de Psicologia e Medicina Comportamental (ABPMC), o binarismo refere-se à divisão, socialmente aceita, da existência de dois gêneros apenas, o masculino e o feminino, ignorando a possibilidade de outras opções, como a dos transexuais. Cumpre salientar que tal concepção viola o princípio da dignidade da pessoa humana, impedindo que o indivíduo tenha o seu direito à felicidade plenamente concretizado. 
que ser diferente é visto como errado, o que demonstra, nitidamente, o desrespeito à diversidade, assim como a negação do direito a ser feliz. Atualmente, a prerrogativa da felicidade é uma das garantias constitucionais no exercício de viabilizar a dignidade humana.

Considerando sua condição existencial peculiar, o transexual, para ter direito ao reconhecimento de sua real identidade, tanto em relação ao nome quanto ao gênero, teria que se submeter a uma cirurgia, a denominada redesignação do sexo ou também conhecida como adequação do sexo anatômico. Nesse ritmo, traz-se à baila a jurisprudência:

REGISTRO CIVIL. Assento de nascimento. Alteração. Pedido de retificação de nome e alteração de sexo no registro civil c c autorização para cirurgia de reatribuição sexual. Inviabilidade. Transexualismo que reclama tratamento médico que só pelo especialista pode ser deliberado. Admissibilidade da cirurgia de transgenitalização mediante diagnóstico específico e avaliação por equipe multidisciplinar, por pelo menos durante dois anos (CFM, Resolução 652/02). [...]. Recorrente que, por ora, é pessoa do sexo masculino. Alteração no registro civil que poderá ser tratada oportunamente após resolvida, no âmbito médico, a questão de transexualidade Apelo desprovido. (Apelação Cível no 417.413-4/5-00, Dois Córregos, Rel. Des. Carvalho Viana, julgado em 09.10.2007). (BRASIL, 2007, on-line).

Frente a essa jurisprudência, nota-se que o indivíduo é obrigado a se submeter a uma cirurgia, para que tenha acesso a direitos e garantias fundamentais, mesmo conhecendo os riscos de um procedimento como esse. Essa exigência contradiz com o que preconiza a CRFB/88, segundo observa a juíza Denise Gondim Mendonça (c 2021):

[...] a Justiça não pode impor que alguém se submeta a intervenção cirúrgica para ter assegurado o direito à própria identidade, vem sendo admitida não só a retificação do nome, mas também da identidade sexual mediante o reconhecimento da identidade social (MENDONÇA, c2021, on-line).

Essa prática de exigência cirúrgica prévia é recorrente mesmo no contexto da CRFB/88. Após várias manifestações e protestos da população LGBTQI+, por meios das conhecidas "paradas gays", o Brasil tem garantido, através de leis, à igualdade, 
no que tange aos direitos dos transexuais; já que os deveres são sempre exigidos, independente de qual seja a opção sexual do indivíduo. Nesse sentido, insta observar que a luta social desse grupo é determinante para a garantia de seus direitos, mesmo após a promulgação da CRFB/88, como observa Alexsandro Soares dos Santos da Silva (2012):

\begin{abstract}
A parada é, hoje, a maior festa política deste país, a favor da liberdade de amar, contra a culpa e em defesa de direitos humanos também para esses coletivos. A multidão que lota anualmente a Avenida Paulista e a Rua da Consolação realiza uma imensa celebração amorosa na contramão da cultura homofóbica, patrocinada pelas religiões cristãs, judaica e islâmica, bem como pela sociedade que insiste em defender a heterossexualidade obrigatória (Rich, 2001). Ela mostra homossexuais e heterossexuais celebrando uma nova compreensão do amor e ensinando ao Brasil e ao mundo a lutar pelo direito de amar - uma proposta política digna de sociedades verdadeiramente justas e democráticas, nas quais o sol realmente nasce para todos. (SILVA, 2012, p.153).
\end{abstract}

Igualar sujeitos diferentes, garantindo-Ihes o direito da plena cidadania, nos mesmos moldes em que os deveres são lembrados, é uma prerrogativa de um Estado Democrático de Direito, como o é a República Federativa do Brasil. Essa consciência coletiva, que proclama o respeito à diversidade, é uma das principais reclamações dessas "paradas" que tem total alinho com a proposta deste trabalho. O direito ao nome social, como importante efetivador da dignidade humana, encaixa-se plenamente nos ideais democráticos da CRFB/88, bem como nas reclamações das "paradas gays". Em consonância com esse entendimento, a Ação Direta de Inconstitucionalidade (ADI) $4275^{8}$ é ajuizada pelo Procurador Geral da República

8 EMENTA: AÇÃO DIRETA DE INCONSTITUCIONALIDADE. DIREITO CONSTITUCIONAL E REGISTRAL. PESSOA TRANSGÊNERO. ALTERAÇÃO DO PRENOME E DO SEXO NO REGISTRO CIVIL. POSSIBILIDADE. DIREITO AO NOME, AO RECONHECIMENTO DA PERSONALIDADE JURÍDICA, À LIBERDADE PESSOAL, À HONRA E À DIGNIDADE. INEXIGIBILIDADE DE CIRURGIA DE TRANSGENITALIZAÇÃO OU DA REALIZAÇÃO DE TRATAMENTOS HORMONAIS OU PATOLOGIZANTES. 1. O direito à igualdade sem discriminações abrange a identidade ou expressão de gênero. 2. A identidade de gênero é manifestação da própria personalidade da pessoa humana e, como tal, cabe ao Estado apenas o papel de reconhecê-la, nunca de constituí-la. 3. A pessoa transgênero que comprove sua identidade de gênero dissonante daquela que the foi designada ao nascer por autoidentificação firmada em declaração escrita desta sua vontade dispõe do direito fundamental subjetivo à alteração do prenome e da classificação de gênero no registro civil pela via administrativa ou judicial, independentemente de procedimento cirúrgico e laudos de terceiros, por se 
(PGR) com o objetivo de dar interpretação do artigo 58 da Lei 6.015/73 compatível como o que determina a CRFB/88. O STF, em primeiro de março de 2018, entende ser possível que haja alteração no prenome e no gênero em registro civil, independentemente de ter ocorrido cirurgia de redesignação sexual.

Antes da publicação do Provimento pelo $\mathrm{CNJ}$, o sujeito deveria ingressar com uma ação judicial, para que o juiz analisasse se ele teria o direito de alterar o nome ou não, devendo, ainda, submeter-se a uma cirurgia de redesignação de sexo com a finalidade de ter seu pleito atendido. Somente após esse processo, o juiz tem o dever de expedir um mandado de averbação, para que o Cartório de Registro civil viabilize o intento. Frente ao exposto, verifica-se clara violação a um direito humano fundamental para a promoção de uma vida digna, trata-se da felicidade do indivíduo, positivada pela CRFB/88, o que faz essa decisão judicial demarcar um importante avanço no que se refere aos direitos dos transexuais no Brasil.

Todavia, apesar de ter sido um posicionamento do STF, em sede de controle concentrado, com efeito erga omnes, precisa de uma regulamentação do CNJ para que seja cumprida pelos Cartórios de Registros Civis do Brasil. Por esse motivo, o CNJ publica o Provimento n.o 73 de 28 de junho de 2018. Este é considerado ato normativo primário, por retirar a validade de seu fundamento diretamente do texto constitucional, não podendo o Cartório se recusar a fazer a alteração nominal, muito menos alegar desconhecimento da decisão do STF e/ou da normativa do CNJ. $\mathrm{Na}$ hipótese de algumas dessas situações acontecerem, o cidadão deve denunciar o caso aos órgãos responsáveis por fiscalizar os cartórios, como as corregedorias dos Tribunais de Justiça, Defensoria Pública e o CNJ.

Em menos de três meses da decisão do STF, o referido Provimento passa regular a troca de nome e gênero em Registro Civil de Pessoais Naturais (RCPN), de forma extrajudicial. Desse modo, concretizam-se os desejos/direitos dos transexuais de alteração do nome e gênero, sem a exigência de cirurgia prévia de

tratar de tema relativo ao direito fundamental ao livre desenvolvimento da personalidade. 4. Ação direta julgada procedente. (BRASIL, 2018, on-line). 
redesignação do sexo, devendo todos os Cartórios de Registros Civis seguirem esse comando normativo.

A determinação, em epígrafe, mostra nítida relação com os anseios de dignidade humana que permeiam a CRFB/88. O nome, além de individualizar a pessoa, é o meio pelo qual ela se identifica, podendo, por isso mesmo, ser determinante para a concretização ou não do seu direito à felicidade. Nesse sentido, no tópico vindouro, verifica-se o modo como o nome e a dignidade humana se relacionam.

\section{O NOME E A DIGNIDADE DOS TRANSEXUAIS}

O nome compõe-se pelo prenome e sobrenome, sendo de supra relevância para o indivíduo em sua vivência em sociedade pelo fato de o particularizar dentre os demais seres, garantindo-lhe os direitos e deveres propostos pela ordem civil. O CC, em seu artigo 16, afirma "Toda pessoa tem direito ao nome, nele compreendidos o prenome e o sobrenome". (BRASIL, 2002, on-line). Segundo Luis Guilherme Loureiro (2013) [...] o nome da pessoa natural é um elemento de identificação, que individualiza o ser humano, distinguindo-o dos demais membros da família e da sociedade. (LOUREIRO, 2013, p.57).

A pessoa, independente de se chamar José, Maria, João, Antônia, traz as marcas de uma individualidade e de seu pertencimento ao mundo, sendo importante na constituição de sua identidade. O nome não é como um acessório, cujo uso é facultativo, de modo que ele não pode divergir do desejo/direito daquele que o detém. É de suma importância ter um prenome e sobrenome, por meio do qual a pessoa se sinta honrada e participe de uma comunidade familiar e social, visto ser direito fundamental.

Por essa via, faz-se necessário diferenciar nome social de nome civil. primeiro está associado a um apelido público e notório, geralmente, muito utilizado pelos transexuais e travestis, como forma de se apresentar na sociedade, sem determinar seu sexo, advindo do nascimento. Já o nome civil, também conhecido como nome registral, regulamentado pela Lei de Registros Públicos e Código Civil 
(CC) de 2002, tem como finalidade identificar e individualizar o indivíduo perante a sociedade. Nesse sentido, Loureiro se posiciona afirmando que "[...] não pode existir pessoa natural sem-nome (necessidade), tampouco é possível a sua renúncia”. (LOUREIRO, 2013, p.57). Os ensinamentos de Débora Silva, Hildeliza Cabral e Carlos Souza (2018) também vão nessa direção:

O nome social é sem dúvidas um grande direito conquistado, que agora passa a ser reconhecido do âmbito do direito ao nome civil, devendo ser registrado no livro em que constam os dados da pessoa que pretende realizar a alteração de nome, permitindo, a partir desse, a troca de todos os demais documentos. (SILVA; CABRAL; SOUZA, 2018, p.74).

Apesar de o direito ao nome ser umas das prerrogativas consolidadas na CRFB/88 como fundamental, os transexuais só têm a garantia desse direito, sem a necessidade de autorização judicial, por meio do Provimento n. ${ }^{\circ}$ 73/2018 do CNJ. Nesse sentido, também determina o Decreto $n .^{\circ} 8.727$, de 28 de abril de 2016:

Art. 1ํ Este Decreto dispõe sobre o uso do nome social e o reconhecimento da identidade de gênero de pessoas travestis ou transexuais no âmbito da administração pública federal direta, autárquica e fundacional. Parágrafo único. Para os fins deste Decreto, considera-se: I - nome social - designação pela qual a pessoa travesti ou transexual se identifica e é socialmente reconhecida; e II identidade de gênero - dimensão da identidade de uma pessoa que diz respeito à forma como se relaciona com as representações de masculinidade e feminilidade e como isso se traduz em sua prática social, sem guardar relação necessária com o sexo atribuído no nascimento. (BRASIL, 2016, on-line).

O Princípio da isonomia (art. 5ำ, caput, CRFB/88) merece uma atenção especial, tratando os iguais na medida da sua igualdade e os desiguais na medida da sua desigualdade, fomentando a realização plena de sua dignidade. Portanto, o objetivo é fazer com que a pessoa se sinta honrada ao obter o reconhecimento de sua real identidade autopercebida e vivida.

Por esse viés, entende-se que a dignidade da pessoa humana é a base do sistema judiciário no Brasil, previsto desde a Lei Maior de 1988, mudando o atual cenário dos transexuais por constitucionalizar os direitos fundamentais, sendo um 
deles o direito ao nome. Desse modo, entende-se a sua relevância no âmbito social, no sentido de que o sujeito é identificado por meio desse nome.

\subsection{DO REGISTRO DE NASCIMENTO}

Geralmente, no momento em que a criança nasce, a primeira pergunta consiste em saber o sexo e a segunda, o nome. Em seguida, é preenchida uma Declaração de Nascido Vivo (DNV). Nela, são contidas todas as informações para registrar uma criança em Cartório. O registro de nascimento, assim chamado, é o primeiro documento do ser humano e, a partir dele, é criada uma identidade de pertencimento social.

Loureiro ressalta "[...] a importância e a obrigatoriedade do assento de nascimento, costumeiramente chamado de primeiro ato da cidadania e, por isso mesmo, gratuito por determinação legal”. (LOUREIRO, 2013, p.57). Assim, é necessário que toda criança, nascida em territorio nacional, deva ser registrada no lugar em que tiver ocorrido o parto ou no local de residência dos pais, conforme o artigo 50 da Lei de Registro Púlicos (LRP). Tanto para a doutrina quanto para a Lei referida, esse procedimento é visto como uma obrigação, pois o registro de nascimento é obrigatório no Brasil. Compete ao Oficial de Registro a lavratura do assento de nascimento após o comparecimento dos pais que são os principais interessados em garantir o direito registral aos seus filhos.

\subsection{DIREITO AO NOME}

A importância de ter o nome na sociedade jurídica reporta à história da própria humanidade. Para distinguir as pessoas entre si, são empregadas, desde tempos pretéritos, denominações que revelam a procedência, identificando famílias e indivíduos. Dada essa relação identitária e essencial para a plenitude da vivência humana, o direito ao nome é tutelado pela CRFB/88. Segundo Flávio Tartuce (2016), esse direito deve ser elencado como um dos grandes ícones que perfaz os direitos da personalidade em favor da pessoa humana. Nessa linha, Tartuce define os direitos da 
personalidade como "[...] aqueles inerentes à pessoa e à sua dignidade [...]". (TARTUCE, 2016, p.146). A sua relevância é tamanha que esse direito é regulado pela esfera pública e, em complementação, pela privada, observada a necessidade de unicidade do sistema jurídico.

A Constituição, no artigo $5^{\circ}$, no Titulo II, que se denomina "Dos direitos e das garantias fundamentais", consagra o direito ao nome, de onde se entende a sua relevância para plena efetivação da dignidade da pessoa humana. Por assim ser, Tartuce adverte: "[...] Nunca se pode esquecer a vital importância do artigo quinto da CRFB/1988 para o nosso ordenamento jurídico, ao consagrar as cláusulas pétreas que são direitos fundamentais deferidos à pessoa". (TARTUCE, 2016, p.145, grifos do autor). Por essa via, o próprio Tartuce (2016) assevera que, em uma perspectiva civilconstitucional, os direitos da personalidade estão para o $\mathrm{CC}$; ao passo que os fundamentais estão para o constitucional. No que se refere aos direitos da personalidade, Tartuce (2016) faz, ainda, a seguite consideração:

Pois bem, os direitos da personalidade são, em suma, aquelas qualidades que se agregam ao homem, sendo intransmissíveis, irrenunciáveis, extrapatrimoniais e vitalícios, comuns da própria existência da pessoa e cuja norma jurídica permite sua defesa contra qualquer ameaça. $O$ direito objetivo autoriza a defesa dos direitos da personalidade, que, por sua vez, são direitos subjetivos da pessoa de usar e dispor daquilo que ele é próprio, ou seja, um poder da vontade do sujeito somado ao dever jurídico de respeitar aquele poder por parte de outrem. (TARTUCE, 2016, p.155).

Entendendo que o direito ao nome está inserido nesse rol, passa-se a analisar as implicações na vida dos transexuais ao terem seu nome, nos documentos oficiais de identificação, divergente da sua identidade autopercebida e vivida em sociedade. Nesse tocante, o sistema judiciário vem trazendo algumas inovações para pessoas transexuais, que tem por objetivo trocar o prenome e o gênero no seu registro civil. No dia vinte e nove de junho de dois mil e dezoito, é publicado, pelo CNJ, um Provimento que regulamenta como deve ocorrer, bem como quais documentos são necessários para obter a permuta nominal e de gênero, em sede de registro no Cartório. 
De acordo com o artigo $2^{\circ}$ do Provimento, é obrigatório ser pessoa maior de 18 anos, ou seja, ter capacidade civil plena, para requerer a averbação do nome e do gênero, com o objeto de adquirir a identidade autopercebida, conforme se observa:

Art. $2^{\circ}$ Toda pessoa maior de 18 anos completos habilitada à prática de todos os atos da vida civil poderá requerer ao ofício do RCPN a alteração e a averbação do prenome e do gênero, a fim de adequá-los à identidade autopercebida.

$\S 1^{\circ}$ A alteração referida no caput deste artigo poderá abranger a inclusão ou a exclusão de agnomes indicativos de gênero ou de descendência. (BRASIL, 2018, on-line).

O assunto é de tamanha relevância, para o indivíduo no processo de vivência em sociedade, que também é regulamentado pela Convenção Interamericana de Direitos Humanos, conferindo à norma valor internacional. Por ser um direito de personalidade, fundamental e inato à pessoa humana tem aplicação imediata conforme narração do art. 5ํ, LXXVII, $\S 1^{\circ}$, da CRFB/88. Assim sendo, o Provimento do CNJ só veio concretizar um direito dos transexuais, já positivado tanto pela CRFB/88 quanto pelas normas internacionais, posto se tratar de direito humano. Pela leitura da normativa, em epígrafe, nota-se a importância do processo de efetivação desse direito dos transexuais, tão discriminados no curso da história. Por assim ser, passa-se a analisar detalhadamente os procedimentos necessários para que seja realizado o processo de alteração nominal de que trata este trabalho.

\section{O PROVIMENTO N. 73 DE 2018 DO CNJ}

Não se reconhecer em um determinado gênero já é motivo de angústia, não conseguir ter um nome condizente com a personalidade que se identifica só traz constrangimento e contar com a demora para conseguir a alteração nominal no registro civil é mais um fator que só potencializa a dor de exclusão social com a qual inúmeros transexuais convivem no Brasil. Por meio dessa narrativa, nota-se a importância do Provimento n. $73 / 2018$, através do qual o CNJ regulamenta forma menos burocrática, mais célere e sem necessidade de cirurgia prévia para que as 
pessoas transexuais possam ter direto de alterar o seu nome e o gênero, em qualquer Cartório de Registro Civil do Brasil.

Segundo a Associação Nacional de Registradores de Pessoas Naturais do Brasil (ARPEN), em pesquisa realizada a pedido da Folha de São Paulo, datada de 27 de junho de 2019, mais de duas mil pessoas transexuais tiveram o direito de alterar o seu respectivo nome, em diferentes Cartórios do Brasil. O número, apesar de expressivo, é pequeno por se tratar de pesquisa em âmbito nacional. Importa destacar que esse dado conta de um ano após a publicação do Provimento, sendo que a cidade de São Paulo sozinha apresenta o número de 1296 pessoas transexuais, ou seja, superior à metade do total de mudança nominal realizada no período da pesquisa supramencionada, que foi de 2019, como já analisado.

A propagação de trabalhos como este só aumenta a publicidade desse direito, possibilitando que outras pessoas também o efetivem, em nítido respeito ao princípio constitucional da dignidade humana. Sendo assim, passa-se a analisar quais procedimentos devem ser adotados pelo requerente, conforme leitura do provimento.

\subsection{DO PROCEDIMENTO EXTRAJUDICIAL}

Para que seja realizada a alteração do prenome do gênero, faz-se necessário que o sujeito vá diretamente ao RCPN, onde está o assento de seu nascimento ou casamento, com o objetivo de solicitar ao Oficial de Registro a devida averbação. Caso o sujeito resida longe da comarca de registro, é permitido, pelo provimento $n .973$ no seu artigo terceiro ${ }^{9}$, que o pedido seja formulado em RCPN diverso daquele no qual o assento é lavrado. Nesse caso, o Oficial de Registro deve encaminhar o requerimento ao oficial competente, através da Central de Informações do Registro Civil (CRC), que é um sistema pelo qual se operacionaliza contato entre os Cartórios.

\footnotetext{
${ }^{9}$ Art. $3^{\circ} \mathrm{A}$ averbação do prenome, do gênero ou de ambos poderá ser realizada diretamente no ofício do RCPN onde o assento foi lavrado.Parágrafo único. O pedido poderá ser formulado em ofício do RCPN diverso do que lavrou o assento; nesse caso, deverá o registrador encaminhar o procedimento ao oficial competente, às expensas da pessoa requerente, para a averbação pela Central de Informações do Registro Civil (CRC). (BRASIL, 2018, on-line).
} 
É preciso salientar que, em caso de envio à oficial de outra comarca, os custos podem ser maiores, devendo o requerente arcar com as custas, desde que seja informado previamente disso. Impera elucidar que a tabela de custas do Tribunal de Justiça (TJ) muda de acordo com cada Estado. Caso o requerente informe que não tenha condições de custear os valores demandados pelo processo administrativo, ele pode anexar, junto ao requerimento de alteração do prenome e do gênero, o pedido de gratuidade de custas do cartório (ANEXO A).

Diante do exposto, fica evidente que o sujeito deve requerer presencialmente em cartório, só assim o registrador civil pode analisar, identificar a pessoa, colher sua qualificação completa e a sua assinatura no requerimento (ANEXO B). A assinatura do pedido de averbação no assento deve ser feita na presença do Registrador conforme mencionado no parágrafo quarto ${ }^{10}$. No termo, a pessoa precisa declarar que não há processo judicial em trâmite para a alteração de prenome e gênero. Em caso de existir alguma demanda em curso, deve ser solicitada a desistência e o arquivamento dela, cabendo ao requerente provar o feito no momento em que for apresentado o pedido extrajudicial.

A averbação do nome e do gênero alterados por transexual é sigilosa e, por isso, não deve constar nenhuma observação sobre isso em sua certidão, de acordo com o artigo quinto ${ }^{11}$ do provimento, a não ser que a pessoa assim o solicite ou em caso de determinação judicial. Os requisitos, para a alteração por via extrajudicial, somente podem ser apresentados por pessoa que tenha 18 anos completos, ou seja, o requerente deve estar habilitado a todos os atos da vida civil. $\mathrm{O}$ oficial de registro, deve verificar, ainda, se o nome e o gênero que o registrado pretende adquirir o difere, de fato, da registral, conforme determina o artigo segundo ${ }^{12}$ do referido Provimento.

10 Art. 4ํำ procedimento será realizado com base na autonomia da pessoa requerente, que deverá declarar, perante o registrador do RCPN, a vontade de proceder à adequação da identidade mediante a averbação do prenome, do gênero ou de ambos. (BRASIL, 2018, on-line).

11 Art. 5 $\mathrm{A}$ alteração de que trata o presente provimento tem natureza sigilosa, razão pela qual a informação a seu respeito não pode constar das certidões dos assentos, salvo por solicitação da pessoa requerente ou por determinação judicial, hipóteses em que a certidão deverá dispor sobre todo o conteúdo registral. (BRASIL, 2018, on-line).

12 Art. $2^{\circ}$ Toda pessoa maior de 18 anos completos habilitada à prática de todos os atos da vida civil poderá requerer ao ofício do RCPN a alteração e a averbação do prenome e do gênero, a fim de adequá-los à identidade autopercebida. (BRASIL, 2018, on-line). 
No entanto, não basta somente ser maior, capaz, ter identidade autopercebida e vivida diferente daquela registrada no seu nascimento. O sujeito deve levar, ao Cartório, uma série de documentos, elencados pelo parágrafo sexto do artigo quarto do provimento, incisos I ao XII ${ }^{13}$, expostos a seguir, para fins de melhor compreensão: certidão de nascimento ou de casamento atualizada, conforme seja o caso; cópia do registro geral de identidade $(R G)$ ou da identificação civil nacional (ICN); cópia do passaporte brasileiro, se for o caso; cópia do cadastro de pessoa física (CPF) no Ministério da Fazenda; cópia do título de eleitor; cópia de carteira de identidade social, se for o caso; comprovante de endereço; certidão do distribuidor cível do local de residência dos últimos cinco anos (estadual/federal); certidão do distribuidor criminal do local de residência dos últimos cinco anos (estadual/federal); certidão de execução criminal do local de residência dos últimos cinco anos (estadual/federal); certidão dos tabelionatos de protestos do local de residência dos últimos cinco anos; certidão da Justiça Eleitoral do local de residência dos últimos cinco anos; certidão da Justiça do Trabalho do local de residência dos últimos cinco anos e a certidão da Justiça Militar, caso se aplique.

Além dos documentos listados no parágrafo anterior, o Provimento, em epígrafe, no artigo sétimo ${ }^{14}$, faculta à pessoa requerente juntar, para instrução do procedimento de alteração nominal, laudo e parecer psicológico que atestem a

${ }^{13}$ Art. 4을 $\mathrm{O}$ procedimento será realizado com base na autonomia da pessoa requerente, que deverá declarar, perante o registrador do RCPN, a vontade de proceder à adequação da identidade mediante a averbação do prenome, do gênero ou de ambos. $\S 1^{\circ} \mathrm{O}$ atendimento do pedido apresentado ao registrador independe de prévia autorização judicial ou da comprovação de realização de cirurgia de redesignação sexual e/ou de tratamento hormonal ou patologizante, assim como de apresentação de laudo médico ou psicológico.§ 20 O registrador deverá identificar a pessoa requerente mediante coleta, em termo próprio, conforme modelo constante do anexo deste provimento, de sua qualificação e assinatura, além de conferir os documentos pessoais originais.§ 300 requerimento será assinado pela pessoa requerente na presença do registrador do RCPN, indicando a alteração pretendida.§ $4^{\circ} \mathrm{A}$ pessoa requerente deverá declarar a inexistência de processo judicial que tenha por objeto a alteração pretendida.§ 50 A opção pela via administrativa na hipótese de tramitação anterior de processo judicial cujo objeto tenha sido a alteração pretendida será condicionada à comprovação de arquivamento do feito judicial.§ $6^{\circ} \mathrm{A}$ pessoa requerente deverá apresentar ao ofício do RCPN, no ato do requerimento, os seguintes documentos:I - certidão de nascimento atualizada;II - certidão de casamento atualizada, se for o caso. (BRASIL, 2018, on-line).

${ }^{14}$ Art. $7^{\circ}$ Todos os documentos referidos no art. $4^{\circ}$ deste provimento deverão permanecer arquivados indefinidamente, de forma física ou eletrônica, tanto no ofício do RCPN em que foi lavrado originalmente o registro civil quanto naquele em que foi lavrada a alteração, se diverso do ofício do assento original. Parágrafo único. O ofício do RCPN deverá manter índice em papel e/ou eletrônico de forma que permita a localização do registro tanto pelo nome original quanto pelo nome alterado. (BRASIL, 2018, on-line). 
transexualidade/travestilidade, assim como laudo médico que comprove a realização de cirurgia de redesignação de sexo. Feita a juntada da documentação, o requerente aguarda o andamento do processo administrativo. Na ausência de um prazo específico previsto pelo Provimento $n .^{\circ} 73$ do $\mathrm{CNJ}$, o Cartório costuma utilizar, de forma análoga, o prazo de 15 (quinze) dias ${ }^{15}$, estabelecido para averbação de registro pelo Código de Normas e Procedimentos dos Serviços Notariais e Registrais do Estado da Bahia (CNP-BA). De igual modo, adota-se o mesmo procedimento para a emissão da certidão averbada, nesse caso, o prazo é de 5 (cinco) dias, conforme artigo $674^{16}$ do CNP-BA, sendo expedida e assinada pelo Oficial de registro ou preposto autorizado, de acordo com o artigo $675^{17}$.

Ainda segundo o Provimento, em seu artigo oitavo ${ }^{18}$, uma vez finalizada a alteração nominal e, devidamente, assentada, o ofício do RCPN às expensas da pessoa requerente, comunica o ato oficialmente aos órgãos expedidores do RG, ICN, CPF e passaporte, bem como ao Tribunal Regional Eleitoral (TRE). Ato contínuo, o requerente deve providenciar a alteração de demais documentos e registros que se refiram à sua identificação. No que tange à averbação do prenome e do gênero alterados na documentação dos descendentes, é preciso que haja a anuência de ambos os pais nas situações em que a prole seja absolutamente incapaz.

Diante disso, resta evidenciado que toda forma de regulamentação do procedimento visa a dar celeridade à alteração nominal, de modo a tornar efetivo o direito à felicidade do indivíduo, como forma de implementar a dignidade da pessoa humana.

Em relação a esse assunto, Taques (2018) afirma:

${ }^{15}$ Art. 791 . O registro e a averbação deverão ser feitos no prazo máximo de 15 (quinze) dias úteis, contado a partir da protocolização. (BRASIL, 2018, on-line).

${ }^{16}$ Art.674. A certidão será, no prazo máximo de cinco(05) dias, lavrada: Art. 674. A certidão será lavrada no prazo máximo de cinco (05) dias úteis. I. em inteiro teor; II. em breve relatório; III. conforme quesitos.

17 Art.675. A certidão será expedida e assinada pelo Oficial de Registro ou preposto autorizado. (BRASIL, 2018, on-line).

${ }^{18}$ Art. 8을 Finalizado o procedimento de alteração no assento, o ofício do RCPN no qual se processou a alteração, às expensas da pessoa requerente, comunicará o ato oficialmente aos órgãos expedidores do RG, ICN, CPF e passaporte, bem como ao Tribunal Regional Eleitoral (TRE). (BRASIL, 2018, online). 
É uma mudança relativamente pequena, mas com grandes impactos na realidade das pessoas trans no Brasil, muitas das quais vivem em situações de extrema fragilidade e não poderiam, de qualquer maneira, se submeter à transgenitalização, ainda que custeada pelo Sistema Único de Saúde. Trata-se de um ato de aceitação da transexualidade, de inserção na sociedade, de adequar a norma à realidade, e não a realidade à norma. É um ato que mais do que regularizar uma situação jurídica, reconhece estas pessoas como detentoras de direitos básicos que desde sempre lhe foram negados: dignidade, igualdade, privacidade e liberdade.

Em outras palavras, fica reconhecido o direito de ser nominado como o sujeito se identifica nos documentos que the possibilitam exercer, com plenitude, os atos da vida civil, independente de autorização judicial e/ou ato cirúrgico de redesignação de sexo prévio.

\section{CONSIDERAÇÕES FINAIS}

O Provimento n. $.^{\circ} 73 / 2018$ do $\mathrm{CNJ}$ traz inovações normativas, no que tange ao direito de alteração do prenome dos transgêneros, nos cartórios de Registro Civil do Brasil, como se verifica a partir da análise da alteração dos prenomes pelos transgêneros, realizada em Cartórios de Registro Civil das Pessoas Naturais do Brasil. Esse imperativo decorre da decisão do STF, em controle abstrato de constitucionalidade, que motiva a edição do Provimento n. ${ }^{\circ} 73$, de 28 de junho de 2018, pelo CNJ.

Frente ao exposto, é notório que, no decorrer dos anos, o direito dos transgêneros vem passando por evoluções. Uma delas é o provimento n. 73 do CNJ que dá autoridade ao indivíduo para realizar alteração do prenome e do gênero sem ser obrigado a fazer cirurgia de redesignação de sexo prévia. Tal regulamentação tem assento no princípio da dignidade humana, constante na CRFB/88, por fazer a pessoa se sentir honrada, considerando suas condições existenciais peculiares, ao obter o direito ao reconhecimento de sua real identidade, tanto em relação ao nome, quanto ao gênero.

Essa grande evolução tem seu substrato na ação direta de inconstitucionalidade que é ajuizada pelo PGR. O STF, em controle abstrato, dá 
interpretação ao artigo 58 do CNP compatível com a CRFB/88, entendendo ser possível que o transexual altere o seu prenome e gênero por via extrajudicial, ou seja, diretamente por meio do Cartório de RCPN, de forma mais célere, menos burocrática, o que enseja o Provimento supra do CNJ. Antes disso, os transgêneros, para alcançarem esse fim, precisavam ingressar com ação judicial, cabendo somente ao juiz analisar se ele tem o direito de alterar o prenome e o gênero. Assim sendo, não depende exclusivamente da sua vontade, mas de uma força maior, a do judiciário.

Apesar do avanço concedido às minorias, a linguagem desse Provimento é muito complexa, além da divulgação ser pouca pelo fato dele ser recente. Somado a tudo isso, sabe-se das condições precárias da educação brasileira e, por isso, muitos transexuais não têm o nível de instrução necessário para compreender o seu direito. Nesse sentido, verifica-se a importância deste trabalho, pois é escrito de forma clara, em linguagem acessível e simples, de modo a dar publicidade a essa regulamentação que positiva direito tão relevante para dignidade humana pela via extrajudicial.

Para alterar o prenome e gênero, é preciso que o requerente seja maior de 18 anos, portador de toda documentação atualizada, que é exigida pelo provimento. Após a juntada do requerimento e documentações, o Oficial(a) de registro faz a devida averbação em registro de nascimento/casamento, emitindo, depois do cumprimento desse trâmite, a certidão alterada. Como se verifica, trata-se de procedimento célere, que chancela direitos da pessoa humana garantidos pela CRFB/88.

\section{REFERÊNCIAS}

BRAZILEIRO, Jhoane Ferreira Fernandes. O direito ao nome e gênero dos transexuais. Disponível em: <http://www.conteudojuridico.com.br/artigo,o-direito-aonome-e-genero-dos transexuais,57873.html>. Acesso em cinco de agosto de 2018.

BRASIL. Conselho Nacional de Justiça. Provimento n. 73, de 28 de junho de 2018. Dispõe sobre a averbação da alteração do prenome e do gênero nos assentos de nascimento e casamento de pessoa transgênero no Registro Civil das Pessoas Naturais (RCPN). Disponível em:

<https://www.anoreg.org.br/site/2018/06/29/provimento-no-73-do-cnj-regulamenta-aalteracao-de-nome-e-sexo-no-registro-civil-2/>. Acesso em vinte de junho de 2020 
Supremo Tribunal Federal. Ação direta de inconstitucionalidade 4275.

RELATOR : MIN. Marco Aurélio. Brasília, 01 de março de 2018. Acesso em vinte de junho de 2020.

- Tribunal de Justiça do Estado da Bahia. CNJ Serviço: Como fazer a troca de nome e gênero em cartórios. Atualizado em: 31 de julho de 2018. Disponível em: <http://www5.tjba.jus.br/corregedoria/cnj-servico-como-fazer-a-troca-de-nome-egenero-em-cartorios/>. Acesso em vinte de junho de 2020.

.Lei no 6.015, de 31 de dezembro de 1973. Disponível em <http://www.planalto.gov.br/ccivil_03/_ato2015-2018/2016/decreto/d8727.htm>. Acesso em três de outubro de 2020.

.Lei $n^{\circ} 10.406$, de 10 de janeiro de 2002. Disponível em <http://www.planalto.gov.br/ccivil_03/leis/2002/L10406compilada.htm>. Acesso em três de outubro de 2020.

.Constituição da república federativa do brasil de 1988. Disponível em <http://www.planalto.gov.br/ccivil_03/constituicao/constituicao.htm>. Acesso em três de outubro de 2020.

BIANQUE, Guilherme Fajardo. O transexual e o direito brasileiro. Disponível em: $<$ https://guifajardo.jusbrasil.com.br/arti,os/336214327/o-transexual-e-o-direitobrasileiro>. Acesso em onze de abril de 2020.

BONAVIDES, Paulo. Curso de direito constitucional. 7. ed. rev., atual. e ampl. São Paulo: Malheiros, 1997.

CAMPOS, Ana Cristina Campos. Corregedoria normatiza mudanca de nome e genero em cartorio. Disponível em:

<http://agenciabrasil.ebc.com.br/geral/noticia/2018-06/corregedoria-normatizamudanca-de-nome-e-genero-em-cartorio >. Acesso em cinco de agosto de 2018.

CHIZZOTTI, Antonio. A pesquisa qualitativa em ciências humanas e sociais: evolução e desafios. Revista Portuguesa de Educação, 2003, 16(2), pp. 221-236, 2003, Universidade do Minho.

GIL, Antônio Carlos. Como elaborar projeto de pesquisa? 4a ed. São Paulo: Atlas, 2002.

GONÇALVES, Carlos Roberto. Teoria Geral das Obrigações. 14aa ed. São Paulo: Saraiva, 2017.

LOUREIRO, Luiz Guilherme. Registros Públicos: Teoria e pratica, $4^{\circ}$ edição. São Paulo:MÉTODO,2013. 
MENDONÇA, Denise Gondim. TJ/GO: Justiça autoriza transexual a mudar nome no registro mesmo sem cirurgia Tribunal de Justiça de Goiás, c2021. Disponível em: https://www.anoreg.org.br/site/2018/06/06/tj-go-justica-autoriza-transexual-a-mudarnome-no-registro-de-nascimento-mesmo-sem-cirurgia/. Acesso em: 30 out. 2021.

MOTTA.Artur Francisco Mori Rodrigues. A dignidade da pessoa humana e suas definições. Disponivel em: <https://ambitojuridico.com.br/cadernos/direitoshumanos/a-dignidade-da-pessoa-humana-e-sua-definicao/>. Acesso em tres de outubro de 2020.

MONTENEGRO, Felipe Mendonça. A realidadedo transexual perante a previdência social. Rio Grande do Sul. 2015.

MODELOSIMPLES. Modelo de Requerimento de Isenção de Taxas do Cartório<https://www.modelosimples.com.br/modelo-de-requerimento-de-isencaode-taxas-docartorio.html>. Acesso em quatorze de novembro de 2020.

MOTA, Júlio "Precisamos de políticas que combatam a transfobia" $<$ https://www2.ufjf.br/noticias/2020/01/30/precisamos-de-politicas-que-combatam-atransfobia/> . Acesso em quatorze de novembro de 2020

RODRIGUES, Marcelo Guimarães. A alteração administrativa do prenome e gênero de transgênero. Disponível em: <https://www.conjur.com.br/2018-ago-03/marcelorodrigues-alteracao-prenome-genero-transgenero $>$. Acesso em vinte de junho de 2020.

SANT'ANA, Mariana Frediani. et. al. Uma discussão sobre identidade de gênero e orientação sexual no Comportamentalismo Radical. In: Bolsoni-Silva, Alessandra Turini et. al. Comportamento em foco 9: análises teóricas, educação e questões sociais. Vol. 9, São Paulo: Associação Brasileira de Psicologia e Medicina Comportamental - ABPMC, 2019.

SANTANA, Raquel Santos de. A dignidade da pessoa humana como princípio absoluto. Disponível em: <https://www.direitonet.com.br/artigos/exibir/5787/adignidade-da-pessoa-humana-como-principio-absoluto $>$. Acesso em vinte de junho de 2020.

SILVA, Débora; CABRAL, Hildeliza; SOUZA, Carlos. O reconhecimento do nome social de pessoas transexuais à luz da decisão do STF que julgou a ADI. 4.275. Vol. 12. Revista Transforma. Itaperuna-RJ,2018.

SILVA, Alessandro Soares da. Memória, Consciência e Políticas Públicas: as Paradas do Orgulho LGBT e a construção de políticas públicas inclusivas. Revista electrónica de psicologia política nº 27, 2012. 
SOUZA, Karol Jefessom Alves de, As diversas manifestações homofóbicas e suas consequências no cotidiano das minorias LGBT. Vol. 2, n 1. 2016.

TARTUCE, Flávio. Direito Civil: Lei de introdução e parte geral, $12^{\circ}$ edição. Rev., atual. e ampl.- Rio de Janeiro:FORENSE,2016.

Taques, João Daniel Vilas Boas. "Trans"cendendo o passado: Uma breve análise do provimento 78 do cnj e a mudança do nome das pessoas trans.

<https://novojurista.com/2018/07/04/transcendendo-o-passado-uma-breve-analise do-provimento-78-do-cnj-e-a-mudanca-do-nome-das-pessoas-trans/>. Acesso em quatorze de novembro de 2020

UNIVERSIDADE DE SÃO PAULO (USP). LGBTQ+ e suas abrangências. 2018. Disponível em <https://prceu.usp.br/uspdiversidade/lgbtq-e-suas-abrangencias/>. Acesso em doze de outubro de 2020.

VELOSO, Patrícia; SOARES, Laiala; JESUS, Geicielly de. Mudança do nome e retificação do gênero no registro civil. Disponível em:

$<$ https://www.anoreg.org.br/site/2018/07/13/artigo-mudanca-do-nome-e-retificacaodo-genero-no-registro-civil-por-patricia-veloso-laila-soares-geicielly-de-jesus/>. Acesso em dois de maio de 2020. 


\title{
UFBA
}

\section{ANEXO A - MODELO DE PEDIDO DE GRATUIDADE DE CUSTAS DO CARTÓRIO}

\author{
ANEXO - MODELO DE PEDIDO DE GRATUIDADE DE CUSTAS DO CARTÓRIO \\ OFICIAL DE REGISTRO CIVIL DAS PESSOAS NATURAIS DO MUNICIPIO \\ DE (AQUI INCLUIR O NOME DA CIDADE DE LOCALIZAÇÃO DO CARTÓRIO)
}

\begin{abstract}
Eu, [Nome social, registrado(a) sob o nome fnome de registrol, Inacionalidadel, [naturalidade], [data e local do nascimento], [estado civil], [profissäol, [RG], [CPF], [endereço comple to], [tele fone], [endereço el etrónico], nesta cidade vem requerer a alteraçào do registro civil na forma do pedido em anexo - ALTERAÇĀO DE REGISTRO CIVIL DE NASCIMENTO COM BASE NO PROVIMENTO N. ${ }^{\circ}$ 73/2018 DA CORREGEDORIA NACIONAL DO CONSELHO NACIONAL DE JUSTIÇA (aqui deve-se anexar o pedido de alteração), de forma gratuita, declarando nos termos da Lei n ${ }^{\circ} 1.060 / 50$, para fins de isenção dos respectivos emolumentos e taxas referentes ao incidente sobre o a to acima descrito, declarando enquadra-se nos termos da lei citada e ainda ciente de que a falsidade da presente declaraçào implicará responsabilidades, podendo ainda o registrador exigir o pagamen to dos emolumentos e taxas correspondentes.
\end{abstract}

Por ser verdade, firmo o presente termo.

Local e data.

Assinatura do requerente

Associação Nacional de Travestis e transexuais - ANTRA. Alteração do Registro civil de pessoas Transexuais e travestis. Projeto eu existo. Rio de Janeiro. 2019. 


\title{
ANEXO B - MODELO DE REQUERIMENTO DE ALTERAÇÃO DE REGISTRO CIVIL
}

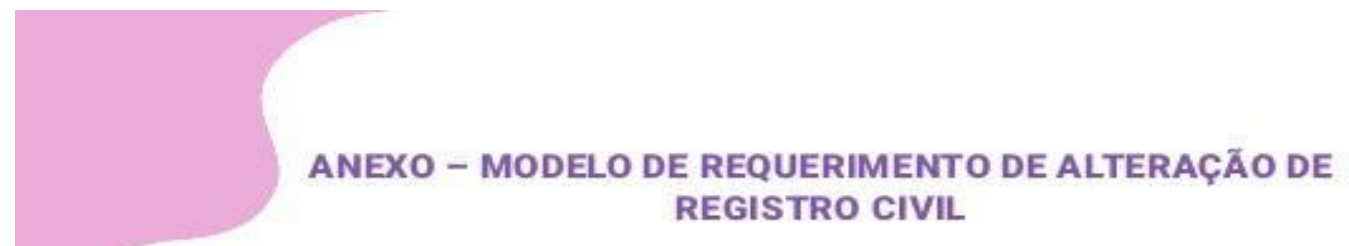 \\ OFICIAL DE REGISTRO CIVIL DAS PESSOAS NATURAIS DO MUNICIPIO \\ DE (AQUI INCLUIR O NOME DA CIDADE DE LOCALIZAÇÃO DO CARTÓRIO) \\ 1-REQUERENTE: \\ Nome civil completo, nacionalidade, naturalidade, data e local do nascimento, estado civil, \\ profissäo, RG, CPF, endereço completo, telefone, endereço eletrônico. \\ II - REQUERIMENTO:
}

Visto que o gênero que consta em meu registro de nascimento não coincide com minha identida de autoperce bida e vivida, solicito que seja averbada a alteração do sexo para (masculino ou feminino), bem como seja alterado o prenome para

III - DECLARAÇÖES SOB AS PENAS DA LEI

Declaro que näo possuo passaporte, identificaçăo civil nacional (ICN) ou registro geral de identidade (RG) emitido em outra unidade da Federaçăo.

ou

Declaro que possuo o Passaporte n. ICN n. e RG $\mathrm{n}$

Estou ciente de que não será admitida outra alteração de sexo e prenome por este procedimento diretamente no registro civil, resguardada a via administrativa perante o juiz corregedor permanente.

Estou ciente de que deverei providenciar a alteraçäo nos demais regis tros que digam respeito, direta ou indiretamente, a minha pessoa e nos documentos pessoais.

Declaro que nâo sou parte em ação judicial em trâmi te sobre identidade de gênero (ou Declaro que o pedido que estava em trâmite na via judicial foi arquivado, conforme certidão anexa.)

IV - FUNDAMENTO JURIDICO

O presente requerimento está fundamentado no principio da dignidade da pessoa humana, no art. 58 da Lei n. $6.015 / 1973$, interpretado pelo Supremo Tribunal Federal no julgamento da ADi n. 4.275, e no Provimento CN-CNJ n. 73/2018.

Por ser verdade, firmo o presente termo.

- Local e data

- Assinatura do requerente

Associação Nacional de Travestis e transexuais - ANTRA. Alteração do Registro civil de pessoas Transexuais e travestis. Projeto eu existo. Rio de Janeiro. 2019. 